\title{
$X$ Ray and Inductively Coupled Plasma Atomic Emission Spectroscopy Analysis of Cristallographic Structure And Composition of Pavement Based Clay Materials
}

\author{
Hilaire Elenga ${ }^{1,}$, , Timothée Nsongo ${ }^{1}$, Bernard Mabiala ${ }^{2}$, David Bilembi ${ }^{2}$, Ferland Ngoro Elenga ${ }^{1}$, \\ Balla Diop Ngom ${ }^{3}$, Aboubaker Chedikh Beye ${ }^{3}$ \\ ${ }^{1}$ Faculty of Sciences and Technics, University of Marien NGOUABI, Brazzaville, Congo \\ ${ }^{2}$ Laboratory of Mechanic, Energy and Engineering, National Polytechnic School, University of Marien GOUABI, Brazzaville, Congo \\ ${ }^{3}$ Department of Physic, Faculty of Sciences and Technologies, University of Cheikh Anta Diop of Dakar, Dakar, Senegal
}

Email address:

nsongo@yahoo.com (H. Elenga), bdngom@gmail.com (B. D. Ngom)

${ }^{*}$ Corresponding authors

\section{To cite this article:}

Hilaire Elenga, Timothée Nsongo, Bernard Mabiala, David Bilembi, Ferland Ngoro Elenga, Balla Diop Ngom, Aboubaker Chedikh Beye. X Ray and Inductively Coupled Plasma Atomic Emission Spectroscopy Analysis of Cristallographic Structure And Composition of Pavement Based Clay Materials. International Journal of Materials Science and Applications. Vol. 6, No. 2, 2017, pp. 83-87. doi: 10.11648/j.ijmsa.20170602.13

Received: December 29, 2016; Accepted: January 12, 2017; Published: February 10, 2017

\begin{abstract}
In order to predicttechnological properties of local clay based materials mixed to wood waste and to prevent human health andenvironment, experimental mineral structure and composition study were conducted. The influence of wood waste on the structural properties of clay samples were also investigated. Non and stabilized clay sample at $4 \%$ of cement were made at different conditions and waste wood at different content have been incorporated. Mineralogical X-ray analysis was carried out using X- raydiffractometer with Geiger counter usingcobalt K $\alpha$ radiationwith wavelength $\lambda=1,789 \AA$. inductively coupled plasma atomic emission spectroscopy (ICP/AES) and inductively coupled plasma optical emission spectroscopy (ICP/OES) were used respectively to determine major, Minor and trace elements. The results showed that incorporation of wood waste has a strong effect on the crystallographic structure, making partially amorphous clay structure. It is found that the waste wood incorporating influence the lattice constants of the components of the clay and must be correlated to acid interaction. Chemical analysis of clay sample indicates kaolinite and $\mathrm{SiO}_{2}$ as a dominant clay minerals. The results has shown some trace and heavy metal contamination for human and environment.
\end{abstract}

Keywords: Clay, Cement, Waste, Wood, Mineral Structure, Structure, Lattice Parameter, X-ray Diffraction

\section{Introduction}

With the development of the wood industry, the abundance of waste wood generate an important environment pollution. A wide range of studies has been reported to recycle wood waste in clay materials in order to improve technological properties $[1,2,4]$. Most of studies focused on mechanical properties and have shown that the addition of wood waste in clay considerably reduced the mechanical strength of the materials [5], [6], [7], [8], [9]. Knowledge of the composition and structural properties of clays mixed with wood waste remains unclear. Most of the research work has been done in order to make bricks $[4,6,8,9]$, pavements $[16,17]$, to study the influence of wood waste on acoustic and magnetic properties [15] or mechanical resistance of bricks or geotechnical structures $[6,8,9]$. There are very few studies in the literature related to the structural properties of clay materials with wood waste incorporating. The results of the study of the structure of clays mixed with wood waste have scientific interest for understanding the physical phenomena observed in the behavior of clay based structures but also to explore new technological applications. To understand the obtained results, chemical analysis should be associated with this study.

Knowledge of the microscopic properties such as structure and composition of clay materials used in construction may have technological interest [3], [10]. This work studies the 
composition of the clay and the influence of waste wood on the structure in order to improve technological properties

\section{Apparatus and Experimental Conditions}

A diffractometerautomated $\mathrm{X}$ type Siemens D5000 equipped with a cobalt anticathode was used the $\mathrm{K} \alpha$ of cobalt with $\lambda=1,79026 \cdot 10^{-10} \mathrm{~m}$ wavelength. The diffracted rays following the Bragg angle was recorded by a counter type GEIGER MULLER. This counter is placed in order to receive the rays diffracted by the sample in terms. The BRAGG law

$2 \mathrm{~d}_{\mathrm{hkl}} \sin \theta=\lambda$ was used to determine the inter-reticular distances. The crystal lattice can be deduced from the expressions (6) and (7). The scanning angle varied between 4 to $84^{\circ} 2 \theta$, the scanning speed was about $0.02^{\circ} 2 \theta$ /second.

\subsection{Ray Mineral Powder Analysis}

For carrying out the analyzes, the samples were previously dried and ground into powder particle size less than $80 \mu \mathrm{m}$. The counting time for this test was about 5 seconds when the sample was turning from 4 to $84^{\circ} 2 \theta$. The crystallized fraction of the samples was determined by X-ray diffractometry from their powder diffractogram. This technique is mainly qualitative and can only give a semi quantitative result. The detection limit is about 5\% and can vary widely depending on the nature of the different phases.

\subsection{X ray Mineral Analysis Using Oriented Blade}

The counting time for this test was about 2 seconds in the rotating sample from 4 to $36^{\circ} 2 \theta$.

The phylliteuse fraction of the samples was determined by diffraction from normal oriented blades glycollées for 12 hours in steam pressure and heated up to $490^{\circ} \mathrm{C}$ for 4 hours.
The composing proportions were estimated from peak areas

\subsection{Method of Identifying Crystal Phases}

Generally the identification of a crystallized phase is made by comparison of the experimental with the theoretical diffractogram. The content of mineral components is estimated from peak areas.

Match 2 software FotoMix!, XRD2DScan were used to analyze the diffraction patterns.

The crystal lattice of $\alpha$ quartz is hexagonal. The values of the lattice constants are obtained after indexing peaks using the expression linking to the interplanar spacing $d_{\mathrm{hkl}}$.

Kaolinite crystallizes in the triclinic system.

Montmorillonite crystallizes in the monoclinic system

Chlorite also crystallizes in the monoclinic system.

\subsection{Spectroscopy Analysis}

Inductively coupled plasma atomic emission spectroscopy (ICP/AES) and inductively coupled plasma optical emission spectroscopy (ICP/OES) were used respectively to determine major, minor and trace elements. The ICP-MS X7 and ICP OES Icap 6500 equipment was used with the following:

$\mathrm{RF}$ power $\sim 1200 \mathrm{~W}$, Plasma argon gas $\sim 151 \mathrm{~min}-1$ ), Auxiliary gas $\sim 0.41 \mathrm{~min}^{-1}$ ), Sample gas $\sim 0.91 \mathrm{~min}^{-1}$ ), Dwell time $\sim 100 \mathrm{~ms}$.

\section{Results and Discussion}

\subsection{Ray Analysis of Clay Sample}

\subsubsection{Raw Clay Sample Structure}

The $\mathrm{X}$ ray pattern of analyzed clay sample before incorporating wood waste are shown in the figure 1 .

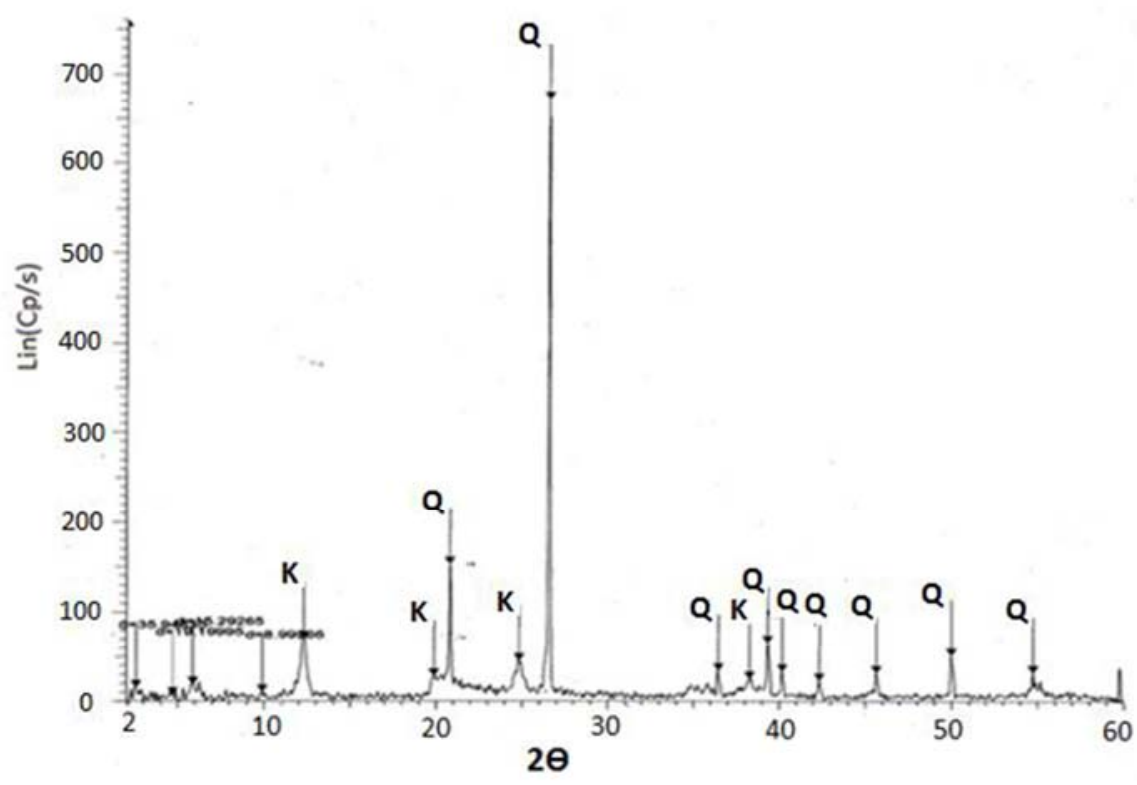

Figure 1. $X$-ray pattern of raw clay sample. 
The results reveals the presence of kaolinite with formula $\mathrm{Al}_{2} \mathrm{H}_{4} \mathrm{Si}_{2} \mathrm{O}_{9}$ and quartz $\alpha$, formula $\mathrm{SiO}_{2}$ in raw clay sample.

Estimates of the concentrations of mineral components obtained using the method of "Peak-height ratio" is as follows:

- Quartz alpha: 51\%;

- Kaolinite: $43 \%$.

- - interstratifiedmontmorillonite/chlorite: $6 \%$

\subsubsection{Clay Sample at 4\% Content of Cement After Acajou Waste Wood Incorporation}

The phases identified are: alpha quartz (Q), formula $\mathrm{SiO}_{2}$; kaolinite, formula.

Al $2\left(\mathrm{Si}_{2} \mathrm{O}_{5}\right)(\mathrm{OH})_{4}$; traces of calcite of formula $\mathrm{CaCO}_{3}$ and anatase of formula $\mathrm{TiO}_{2}$. Traces of calcite and anatase are due to the presence of the cement used to stabilize the mixture clay- soil-cement-woodchips.

- Quartz alpha: 58\%;

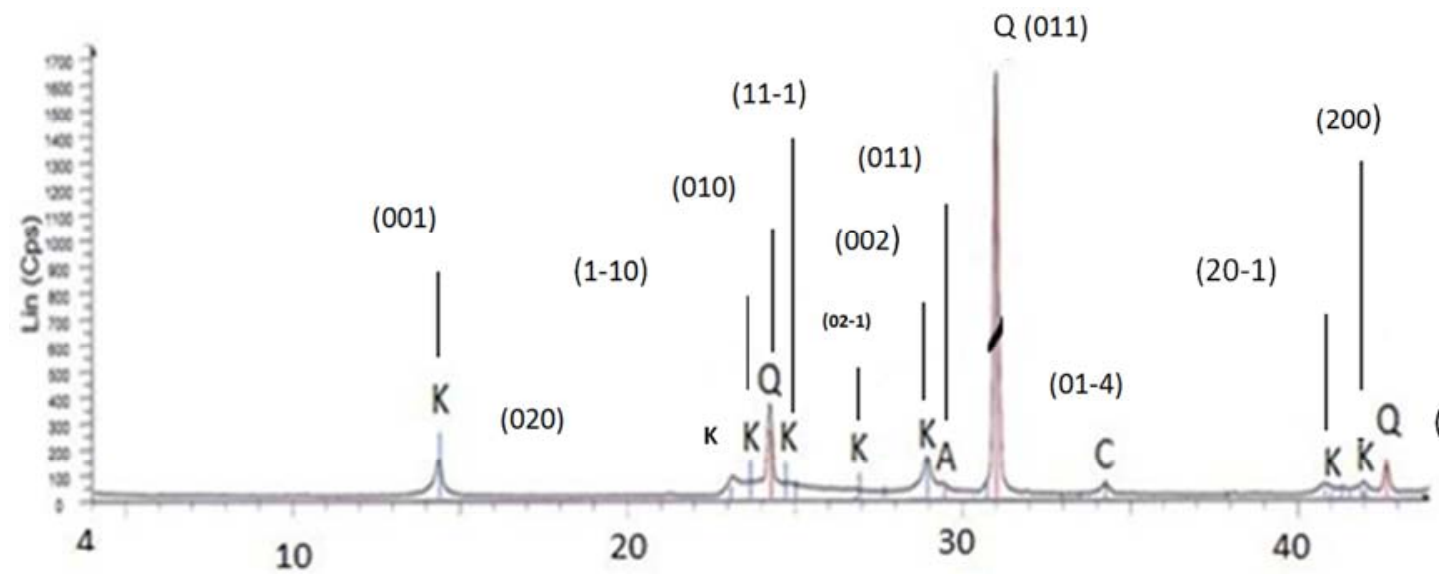

Figure 2. X Ray pattern after wood waste of limba incorporation.

\subsection{Determination of Lattice Constants of Clay Components}

Experimental lattice constants before and after waste wood incorporation was measured using $\mathrm{d}_{\mathrm{hkl}}$, the results are summarized in the table 3 .

Table 1. Theoretical experimental lattice constants before and after waste wood incorporation.

\begin{tabular}{lllll}
\hline & Quartz $\boldsymbol{\alpha}$ & & Kaolinite \\
\hline & Before incorporating waste & After incorporating waste & Before incorporating waste & After incorporating waste \\
\hline \multirow{2}{*}{$\begin{array}{l}\text { Experimental lattice } \\
\text { constants }(\dot{A})\end{array}$} & $\mathrm{a}=\mathrm{b}=4,92$ & $\mathrm{a}=\mathrm{b}=5,52$ & $\mathrm{a}=5,14$ \\
& $\mathrm{c}=5,66$ & $\mathrm{c}=5,68$ & $\mathrm{~b}=8,86$ & $\mathrm{a}=5,59$ \\
Theoretical lattice & $\mathrm{a}=\mathrm{b}=4,91$ & & $\mathrm{c}=7,50 \quad \mathrm{~b}=9,68$ \\
constants $(\dot{A})$ & $\mathrm{c}=5,40$ & $\mathrm{a}=\mathrm{b}=4,91$ & $\mathrm{a}=5,13$ & $\mathrm{c}=7,31$ \\
& & $\mathrm{c}=5,40$ & $\mathrm{~b}=8,89 \quad \mathrm{~b}$ & $\mathrm{c}=8,89$ \\
\hline
\end{tabular}

For the parameters $a$ and $b$, the resulting values are identical to the results achieved by [12] in the case of $\alpha$ quartz, kaolinite and montmorillonite. There is no change on a and c lattice constant of chlorite conversely to lattice parameter a, c of quartz, kaolinite and montmorillonite. So then we can say that there has been an expansion of the crystal lattice; while in the case of chlorite this variation is observed in the parameter $b$, in this case we see a compression which results in a reduction of the volume of the
- Kaolinite: $24 \%$;

- Some traces of anatase: $8.88 \%$ and calcite: $8.31 \%$.

By comparing the concentrations of mineral components of the crude clay and clay after incorporation of wood waste, we find that:

The concentration of $\mathrm{SiO}_{2}$ (quartz) in the crude clay (51\%) is weaker than that with the clay after incorporating of mahogany wood waste $(58 \%)$. Chemical reactions between clay and cement with high levels (pozzolanic reactions) form of new products that contribute to the strength of a cement stabilized earth [Akpodje 1985]; [Bell 1996].

Clay paved samples were analyzed by X-ray, after incorporating wood waste. The obtained results are shown in Figure 2.

The results showed that incorporation of wood waste has a strong effect on the crystallographic structure, making partially amorphous clay structure.

\section{$Q$ (011)}

(110) crystal lattice.

A very little change of the experimental lattice constant was observed both for quartz and kaolinite. These results is in agreement with those obtained by [13] and are discussed as interactions of heavy metals cations with kaolinite could affect the structure of kaolinite.

"a" and "b" lattice constants were found to be high after waster wood incorporating. It was found [4] that waste wood incorporating in clay make it highly acidic, according. 
Dorothy Carroll et al [14] have shown that the acid attach has an influence in clay structure. The lattice constant expansion must be interpreted in acid reaction.

\subsection{Composition Determination of Clay Sample}

Chemical composition was determined by spectroscopy following the procedure NF P94-048.

The results obtained are summarized in the tables 2 and 3 .

The results indicated the presence of $\mathrm{SiO}_{2}, \mathrm{Al}_{2} \mathrm{O}_{3}$ and $\mathrm{Fe}_{2} \mathrm{O}_{3}$ as major oxides.

And some traces of $\mathrm{MnO}, \mathrm{MgO}, \mathrm{CaO}, \mathrm{Na}_{2} \mathrm{O}, \mathrm{K}_{2} \mathrm{O}, \mathrm{TiO}_{2}$, $\mathrm{P}_{2} \mathrm{O}_{5}$ in the form of impurities.

Table 2. Values of traceelements.

\begin{tabular}{|c|c|c|c|c|c|c|c|}
\hline As & Ba & $\mathrm{Be}$ & $\mathbf{B i}$ & Cd & $\mathrm{Ce}$ & Co & $\mathrm{Cr}$ \\
\hline ppm & ppm & ppm & ppm & ppm & ppm & ppm & ppm \\
\hline 0,8007 & 117,1714 & 0,7561 & 0,2981 & 0,0743 & 40,2884 & 4,26 & 70,5524 \\
\hline Cs & $\mathrm{Cu}$ & Dy & Er & $\mathbf{E u}$ & Ga & Gd & Ge \\
\hline ppm & ppm & ppm & ppm & ppm & ppm & ppm & ppm \\
\hline 3,3022 & 11,9149 & 1,8503 & 0,9722 & 0,6891 & 35,7462 & 2,1793 & 2,1976 \\
\hline $\mathrm{Hf}$ & Ho & In & La & Lu & Mo & $\mathbf{N b}$ & Nd \\
\hline ppm & ppm & ppm & ppm & ppm & ppm & ppm & ppm \\
\hline 7,1513 & 0,3574 & 0,0476 & 28,9338 & 0,1652 & 1,4584 & 18,1847 & 16,9186 \\
\hline $\mathrm{Ni}$ & $\mathbf{P b}$ & Pr & $\mathbf{R b}$ & Sc & Sb & Sm & Sn \\
\hline ppm & ppm & ppm & ppm & ppm & ppm & ppm & ppm \\
\hline 22,3332 & 18,9889 & 4,9762 & 15,2104 & 10,3 & 0,1421 & 2,9101 & 2,4378 \\
\hline $\mathrm{Sr}$ & Ta & Tb & Th & $\mathbf{T m}$ & $\mathbf{U}$ & $\mathbf{V}$ & W \\
\hline ppm & ppm & ppm & ppm & ppm & ppm & ppm & ppm \\
\hline 33,4639 & 1,6413 & 0,3112 & 6,7255 & 0,146 & 2,1038 & 74,7965 & 2,4262 \\
\hline $\mathbf{Y}$ & & $\mathbf{Y b}$ & & $\mathbf{Z n}$ & & c & \\
\hline ppm & & ppm & & ppm & & ppm & \\
\hline 8,6069 & & 1,0443 & & 56,3158 & & 269,7383 & \\
\hline
\end{tabular}

Fourty four trace elements were determinated using ICP/AES, the obtained results are in agreement with those published by Jean Carignan et al. [11]. Among all these impurities, Heavy metals such $\mathrm{Sb}, \mathrm{Cr}, \mathrm{Cu}, \mathrm{Pb}, \mathrm{Zn} \mathrm{Co}$ and $\mathrm{Ni}$ has found to be toxic for human and environment [12].

The table 3 show the analysis results of major and minor elements, most of them like ceramics are very useful for industry applications.

Table 3. Values of major and minor constituents.

\begin{tabular}{|c|c|c|c|c|c|c|c|c|c|c|c|c|}
\hline $\begin{array}{l}\text { Eléments } \\
\text { chimiques }\end{array}$ & $\mathrm{SiO}_{2}$ & $\mathrm{Al}_{2} \mathrm{O}_{3}$ & $\mathrm{Fe}_{2} \mathrm{O}_{3}$ & MnO & MgO & $\mathrm{CaO}$ & $\mathrm{Na}_{2} \mathrm{O}$ & $\mathbf{K}_{2} \mathrm{O}$ & $\mathrm{TiO}_{2}$ & $\mathbf{P}_{2} \mathbf{O}_{5}$ & PF & Total \\
\hline & $\%$ & $\%$ & $\%$ & $\%$ & $\%$ & $\%$ & $\%$ & $\%$ & $\%$ & $\%$ & $\%$ & $\%$ \\
\hline & 55,22 & 25,91 & 2,90 & < L.D. & 0,20 & 0,09 & < L.D. & 0,31 & 1,27 & < L.D. & 13,90 & 99,80 \\
\hline
\end{tabular}

These results can be discussed according the experimental lattice constant values and can affect clay properties after waste wood incorporating. Recently the research work of SOUMIKA MBAYA [15] has shown the incorporation of waste wood in clay increase the magnetic induction. The determination of the trace element must have a correlation with magnetic properties.

\section{Conclusion}

At the end of this study, these conclusions can be drawn: Makoua clay consists of the following minerals unevenly distributed: the quartz $\alpha$, kaolinite, and interstratified chlorite/ montmorillonite which crystallize respectively in the hexagonal, triclinic and monoclinic system.

In this study, we have determined the mineralogical structure of the Makoua clay and the lattice constant of the components of this clay using the mineralogical analysis by $\mathrm{X}$-ray powder and oriented blades.

The results showed that incorporation of wood waste has a strong effect on the crystallographic structure, making partially amorphous clay structure. It is found that the lattice constants increase of quartz and kaolinite after waste wood incorporating must be correlated to the acid interaction.

Chemical analysis of clay sample indicates kaolinite and $\mathrm{SiO}_{2}$ as predominant component.

Some trace and heavy contamination has been identified to be toxic for some industry activities.

\section{Acknowledgements}

The authors would like to express their gratitude to Research Center of Geological and Mining Research for the financial support of the project. 


\section{References}

[1] Gilbert GANGA, (2016), Study of the influence of wood waste content on the mineralogical structure, mechanical and acoustic properties of clay and laterite bricks. $\mathrm{PhD}$ Thesis, Marien NGOUABI University, Congo.

[2] Gilbert Ganga, Timothée Nsongo, Hilaire Elenga, Bernard Mabiala, Thomas Tamo Tatsiete, Nzonzolo, Effect of incorporation of wood chips and sadwust mahogamy on mechanical and acoustic behaviour of brick clay, oral communication, The 2nd Annual Conference on Engineering and Information Technology, Tokyo, Japan 28-30 March 2014, Journal of Building Construction and Planning Research, 2014, 2, 198-208.

[3] Timothée Nsongo (1987), Study of the structure and adhesion of thin films of titanium and titanium nitride prepared by radiofrequency magnetron sputtering and by triode in direct current, doctoral Thesis (University of Aix-Marseille III France).

[4] Gilbert Ganga*, Hilaire Elenga, Timothée Nsongo, Thomas Tamo Tatsiete, Effect of environmental temperature and $\mathrm{pH}$ water on compressive strength of clay brick mixed wood chips mahogamy based building materials, The SIJ Transactions on Industrial, Financial \& Business Management (IFBM), Vol. 2, No. 6, August 2014.

[5] Errais E. (2011), Surface reactivity of natural clays. Study of the absorption of anionic dyes. Doctoral Thesis, University of Strasbourg, France, 36-46, 76-77p.

[6] Ganga G. (2013), Impact of wood waste on the mechanical and acoustic properties of stabilized earth bricks. Master's thesis, Ecole Nationale Supérieure Polytechnique University of Yaoundé 1.

[7] Khelifi W. et Belouettar R. (2012): Influence of the nature of wood chips on the physical and mechanical characteristics of wood chip concretes. $20^{\text {th }}$ University Meeting of Civil Engineering, Chambéry France.

[8] Meukam P. (2004). Characterization of local materials for the thermal insulation of buildings. PhD Thesis University of Yaoundé I, Cameroon. 140p.

[9] Taoukil D. et al (2011): Mechanical and hydric characterization of a lightweight concrete with wood residues. International Heliotechnical Review No. 43.

[10] Truche C. (2010). Characterization and quantification of clay minerals in expansive soils by infrared spectroscopy at laboratory and field scales. Doctoral Thesis, Toulouse University 3 Paul Sabatier, France, 52-60p.

[11] Jean Carignan, Pascal Hild, Guy Mevelle, Jacques Morel and Delphine Yeghicheyan (2001), Routine Analyses of Trace Elements in Geological Samplesusing Flow Injection and Low Pressure On-Line Liquid Chromatography Coupled to ICPMS: A Study of geochemical reference materials BR, DR-N, UB-N, AN-G and GH, TheJournal of geostandards and geoanalysis, vol. 25, $\mathrm{n}^{0} 2-3$, p. 187-198.

[12] Xiarou Wand et al. (1999), Trace metals in traditional Chinese medicine: A preliminary study using ICP-MS for metal determination and As, Atomic spectroscopy, vol 20 (3).

[13] Miranda - Trevino Jorge C., Coles Cinthia A. (2003), kaolinite properties, structure and influence of metal retention, Applied clay science 23, 133-139p.

[14] Dorothy Carroll, Harry C. Stakey (1971), Reactivity of clay minerals with acids and alkalies, Clays and clay minerals, 19, 321-333p.

[15] Soumika Mbaya Rubens (2016), Influence of the wood waste content on the acoustic and magnetic properties of bricks in cement stabilized clay, Master in science, Marien NGOUABI University, Congo, $38 \mathrm{p}$.

[16] Ngoro Elenga F. et al. (2016), The influence of the nature of plant and mineral waste on clay slab resistance to flexion traction, research journal of Material sciences, 4 (9) 1-5 p.

[17] Ngoro Elenga F. et al. (2016), Experimental study on the effect of wood sawdust and sand on the clay slab resistance to compression, research journal of engineering sciences, 5 (11) 13-16 p. 